\title{
MANUAL DE PRÁTICAS EM EDUCAÇÃO FÍSICA NA EDUCAÇÃO PROFISSIONAL E TECNOLÓGICA UTILIZANDO O APLICATIVO GRATUITO EFE - EPTFIS
}

\section{ARTIGO ORIGINAL}

VIANA, Valderi Nascimento ${ }^{1}$, FECURY, Amanda Alves ${ }^{2}$, OLIVEIRA, Euzébio de ${ }^{3}$, DENDASCK, Carla Viana ${ }^{4}$, DIAS, Claudio Alberto Gellis de Mattos ${ }^{5}$

VIANA, Valderi Nascimento. Et al. Manual de práticas em Educação Física na Educação Profissional e Tecnológica Utilizando o Aplicativo Gratuito EFE EPTFis. Revista Científica Multidisciplinar Núcleo do Conhecimento. Ano 06, Ed. 04, Vol. 05, pp. 65-76. Abril de 2021. ISSN: 2448-0959, Link de acesso: https://www.nucleodoconhecimento.com.br/educacao-fisica/manual-de-praticas, DOI: 10.32749/nucleodoconhecimento.com.br/educacao-fisica/manual-de-praticas

\section{RESUMO}

O aplicativo, EFE-EduFisEPT, age como suporte para as atividades escolares de educação física, utilizando a pedagogia histórico-critica ocorre o confronto dos saberes científicos do professor com os saberes empíricos dos alunos, ocasionando o desenvolvimento de uma nova visão e atuação em sociedade. O objetivo deste manual é orientar o docente de Educação física acerca do conteúdo e práticas para

\footnotetext{
${ }^{1}$ Educador Físico, Especialista em Fisiologia do Exercício e Nutrição Esportiva (FAMA), Discente do Programa de Pós-Graduação em Educação Profissional e Tecnológica (PROFEPT IFAP).

${ }^{2}$ Biomédica, Doutora em Doenças Tropicais, Professora e pesquisadora do Curso de Medicina do Campus Macapá, Universidade Federal do Amapá (UNIFAP).

${ }^{3}$ Biólogo, Doutor em Doenças Tropicais, Professor e pesquisador do Curso de Educação Física da, Universidade Federal do Pará (UFPA).

${ }^{4}$ Teóloga, Doutora em Psicanálise Clínica. Atua há 15 anos com Metodologia Científica ( Método de Pesquisa) na Orientação de Produção Científica de Mestrandos e Doutorandos. Especialista em Pesquisas de Mercado e Pesquisas voltadas a área da Saúde.

${ }^{5}$ Biólogo, Doutor em Teoria e Pesquisa do Comportamento, Professor e pesquisador do Curso de Licenciatura em Química do Instituto de Ensino Básico, Técnico e Tecnológico do Amapá (IFAP) e do Programa de Pós Graduação em Educação Profissional e Tecnológica (PROFEPT IFAP).
}

RC: 82194

Disponível em: https://www.nucleodoconhecimento.com.br/educacao-fisica/manual- 
aulas de educação física em EPT e quanto a funcionalidade do aplicativo gratuito EFE - EPTFis. Com sua interface simples, o uso do aplicativo se torna fácil e com funcionalidades intuitivas. Este produto educacional existe como suporte para que o professor desenvolva uma educação física mais crítica, que entenda o aluno além do ser biológico, ou seja, um ser social, político, cultural e histórico. Em que cada aula, o aluno poderá compreender que o conteúdo apresentado está ligando a várias dimensões da realidade, contribuindo para uma visão de sociedade baseada em valores e atitudes para o objetivo comum: conhecimento para gerar menos exclusões e discriminações.

Palavras-chave: Educação Física, Prática, EPT, Formação

\section{INTRODUÇÃO}

O aplicativo, EFE-EduFisEPT, foi pensado como suporte para as atividades escolares de educação física, visando trabalhar esse componente curricular em sua totalidade, proporcionando assim uma formação humana, integral e omnilateral aos alunos do ensino médio da educação profissional e tecnológica (EPT) (VIANA e DIAS, 2020).

Dessa forma, utilizando a pedagogia histórico-critica ocorre o confronto dos saberes científicos do professor com os saberes empíricos dos alunos, ocasionando o desenvolvimento de uma nova visão e atuação em sociedade (SILVA, 2017; ANDRADE et al., 2020).

Além, de suporte pedagógico, o aplicativo serve como um meio de divulgação do conhecimento científico, pois todas as aulas estão baseadas nessa forma de conhecimento. Por ser um aplicativo, há uma maior facilidade de acesso de qualquer parte do mundo (via aparelhos de telefonia celular, tablets, computadores e afins), tornando esse conteúdo acessível, aproximando o usuário da comunidade científica,

RC: 82194

Disponível em: https://www.nucleodoconhecimento.com.br/educacao-fisica/manual- 
atualizando seus saberes. Instiga o usuário a ser um conhecedor e ter um maior interesse para realizar um trabalho pedagógico diferenciado (SANTOS et al., 2018).

\section{OBJETIVO}

Orientar o docente de Educação física acerca do conteúdo e práticas para aulas de educação física em EPT e quanto a funcionalidade do aplicativo gratuito EFE EPTFis

\section{MATERIAIS E MÉTODOS}

O aplicativo aqui descrito pode ser baixado gratuitamente em https://play.google.com/store/apps/details?id=com.ifap.efe (Play Store), exclusivamente para Android. O conteúdo total pode ser acessado gratuitamente no endereço https://www.edufisept.com.br/ .

\section{O APLICATIVO E SEU CONTEÚDO}

\section{O APLICATIVO}

O aplicativo foi pensado, assim como o site, para dar ao profissional que trabalha (ou não) com Educação Profissional e Tecnológica (EPT) uma ferramenta teórico prática a fim de contribuir com a formação humana, integral e omnilateral de discentes (VIANA et al., 2020).

O passo-a-passo que se segue procura facilitar o trabalho de profissionais que tem menor afinidade com este tipo de tecnologia.

RC: 82194

Disponível em: https://www.nucleodoconhecimento.com.br/educacao-fisica/manual- 
Figura 1 Mostra a interface de entrada do aplicativo. Para visualização do menu deve-se deslizar a tela da esquerda para a direita.
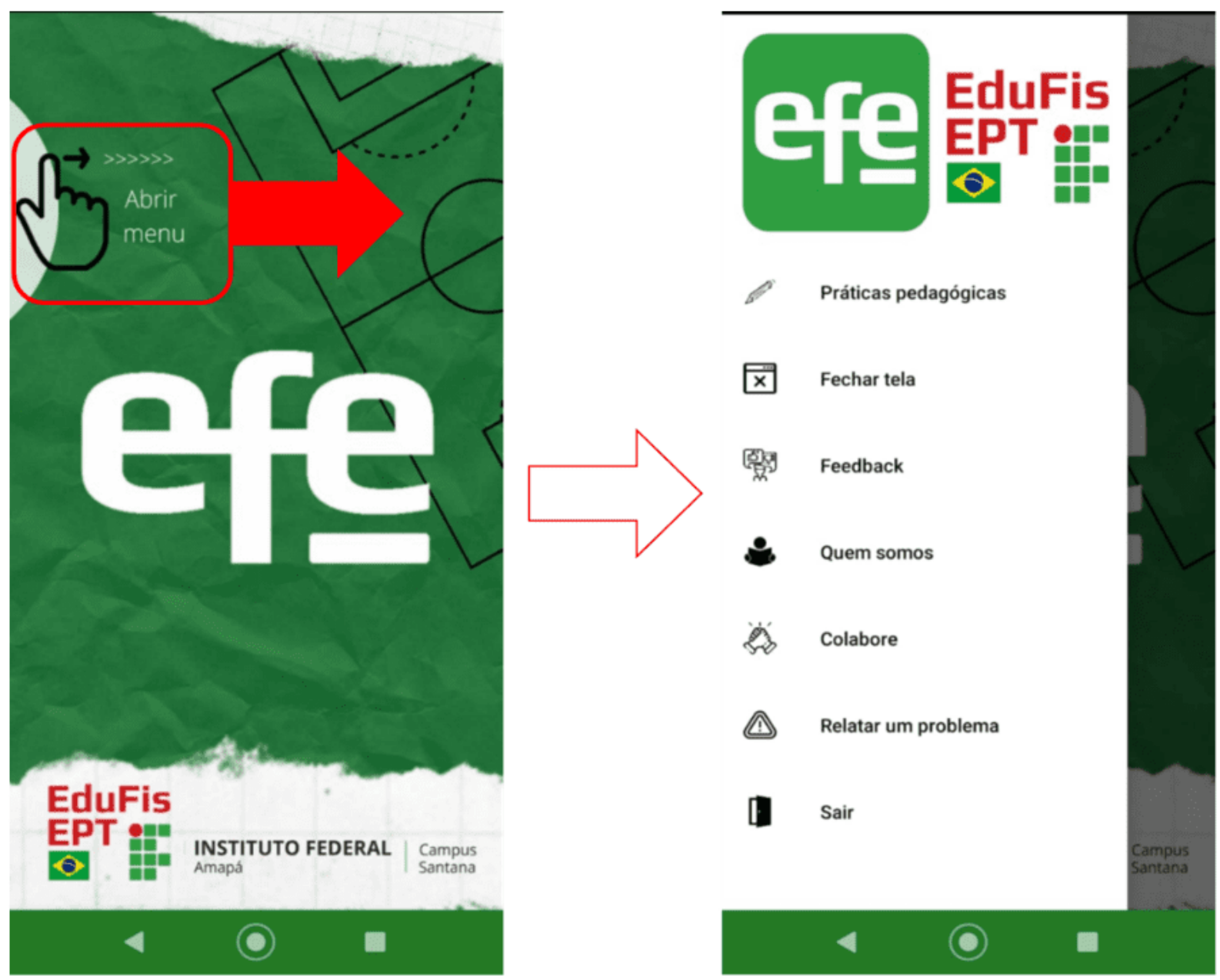

RC: 82194

Disponível em: https://www.nucleodoconhecimento.com.br/educacao-fisica/manual- 
Figura 2 Mostra o que acontece quando clicamos em "Práticas pedagógicas" no menu. Abre-se uma outra tela onde é possível selecionar o tipo de prática.
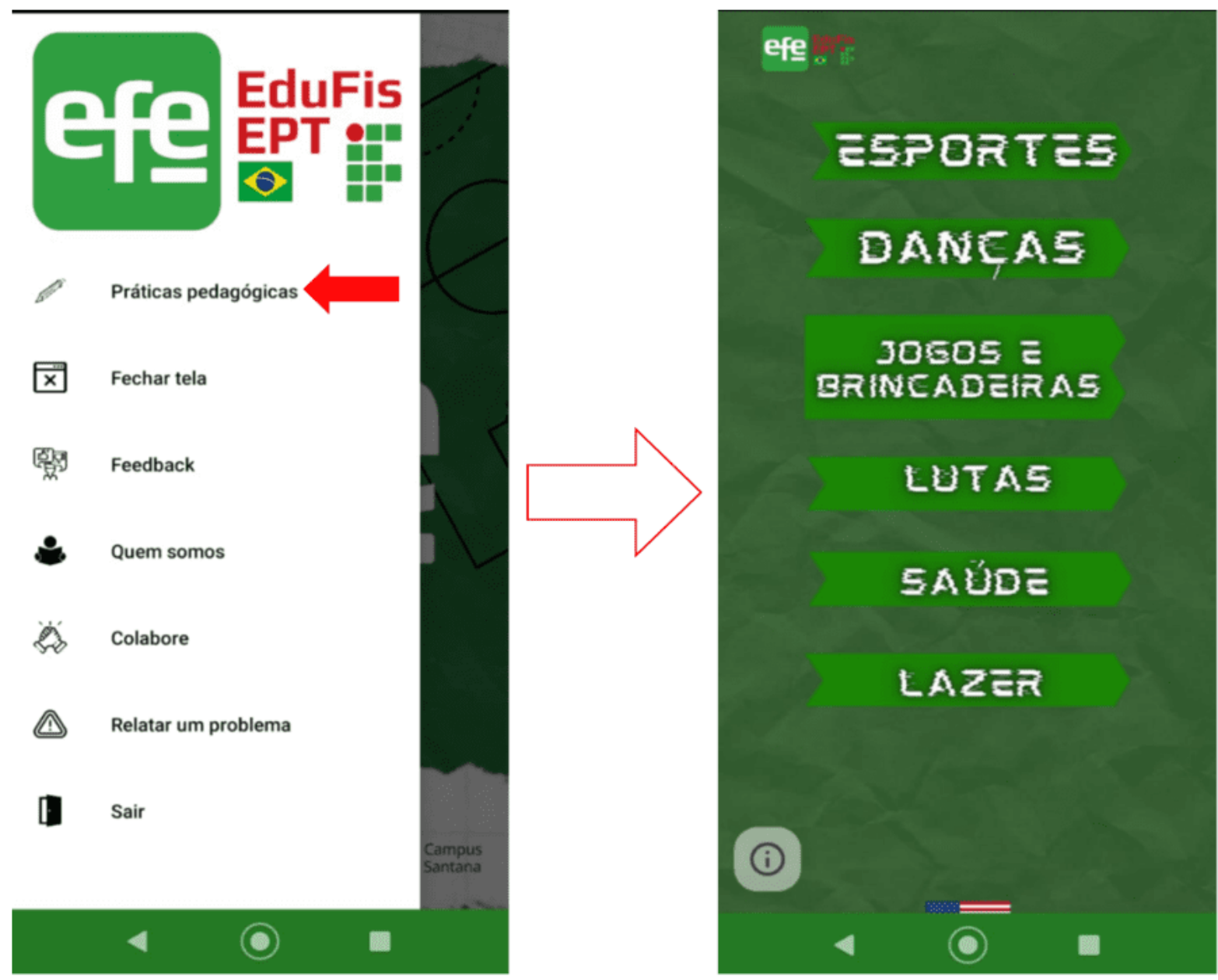

RC: 82194

Disponível em: https://www.nucleodoconhecimento.com.br/educacao-fisica/manualde-praticas 
Figura 3 Mostra que, clicando em cada item, existem botões para acessar a teoria que o compõe e a prática em si, a serem conduzidas com os discentes.

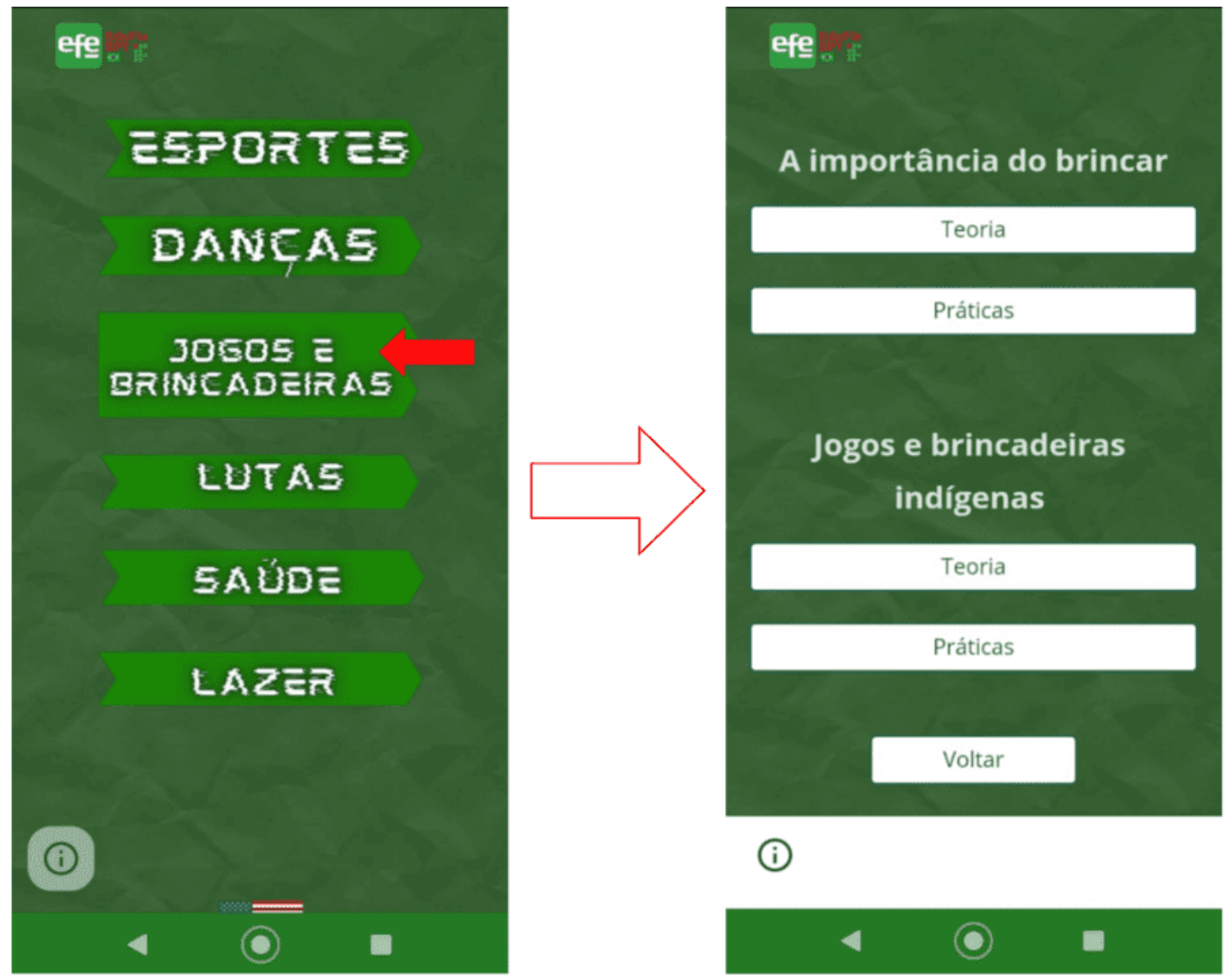

RC: 82194

Disponível em: https://www.nucleodoconhecimento.com.br/educacao-fisica/manualde-praticas 
Figura 4 Mostra que, ao clicar em "Teoria", é disponibilizada uma aba com a teoria fundamentada e, também, vídeo documentários para melhor compreensão da parte prática.

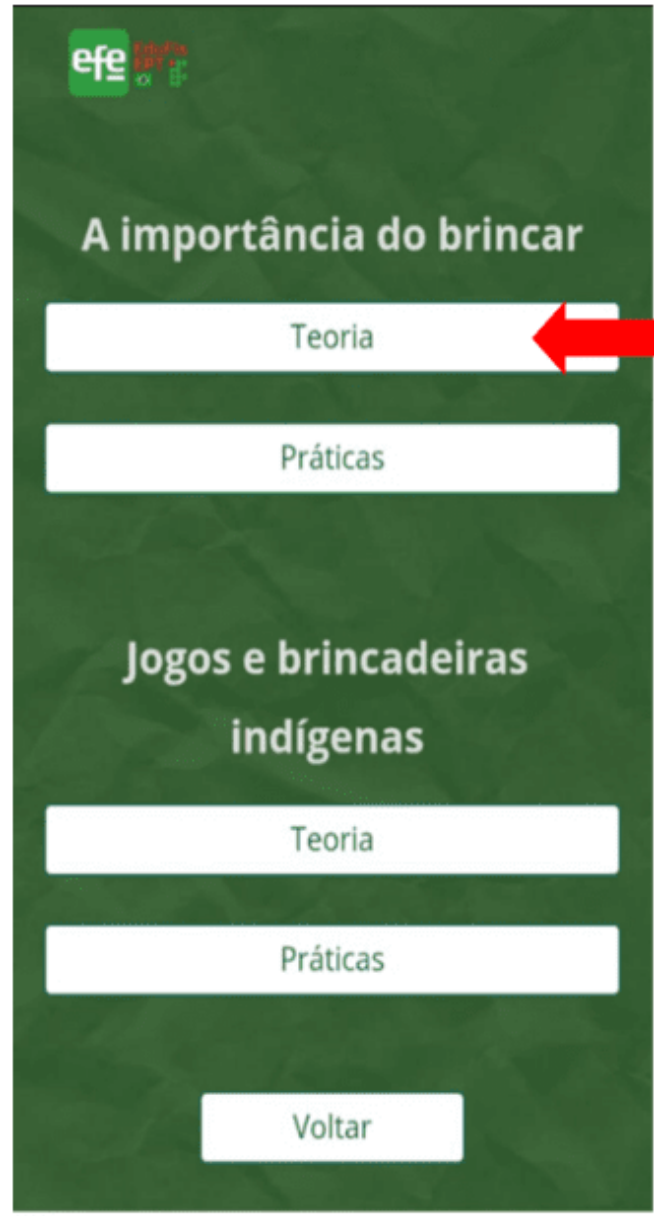

(i)

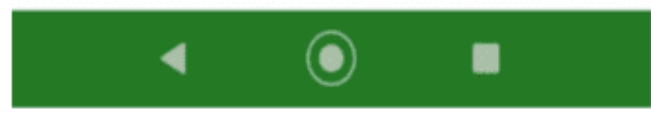

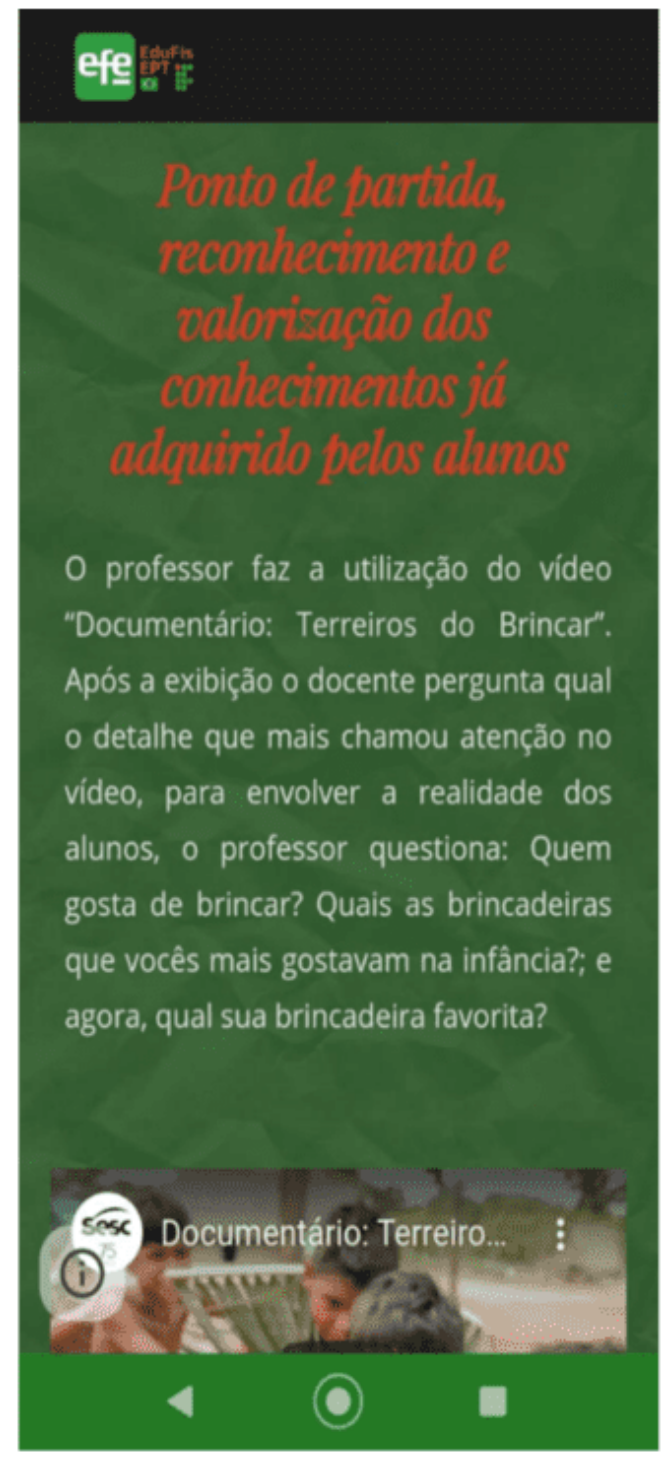

RC: 82194

Disponível em: https://www.nucleodoconhecimento.com.br/educacao-fisica/manualde-praticas 
Figura 5 Mostra que, ao clicar em "Prática", abre-se uma nova tela onde várias práticas possíveis são apresentadas.

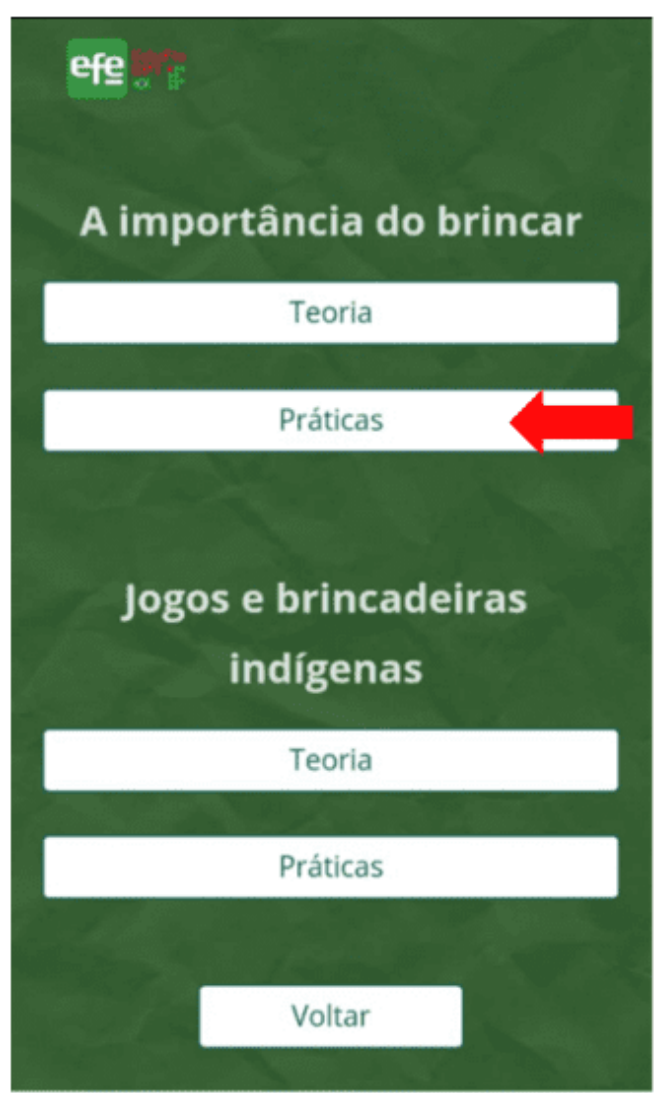

(i)

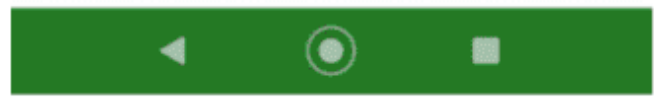

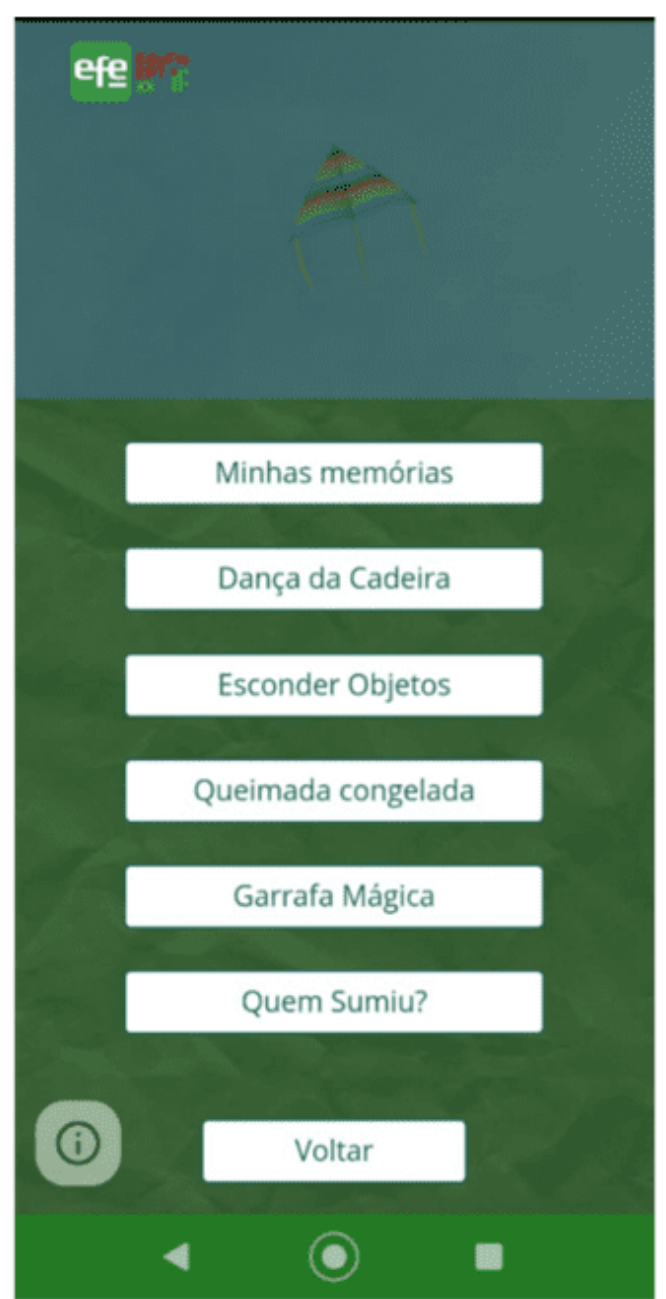

RC: 82194

Disponível em: https://www.nucleodoconhecimento.com.br/educacao-fisica/manualde-praticas 
Figura 6 Mostra que, ao clicar em, por exemplo, "Queimada Congelada", abre-se uma nova tela onde, para cada prática existe um item que mostra os recursos necessários a ela, a descrição detalhada e uma dica útil. Este formato se repete em todas as demais práticas do aplicativo.
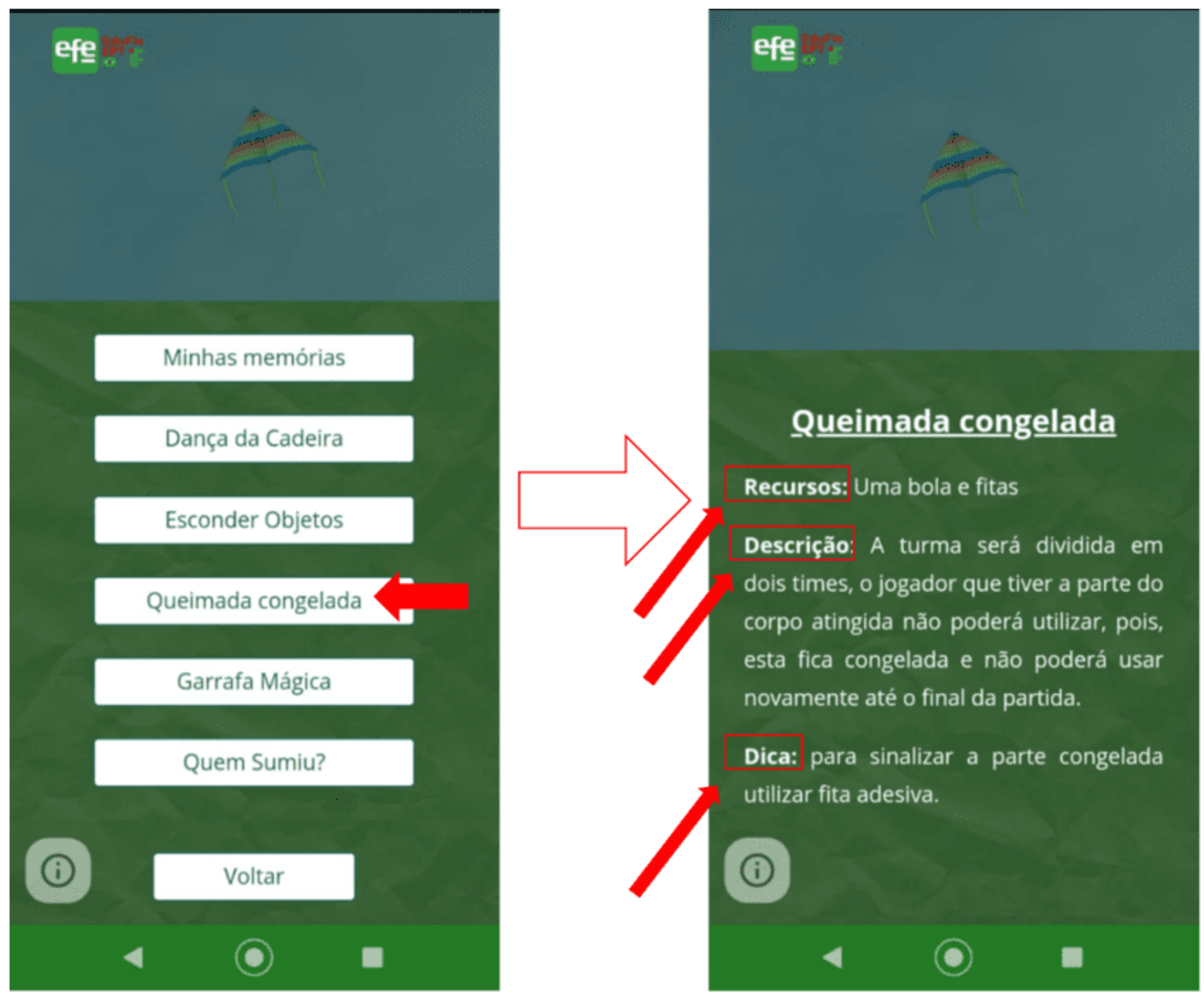

RC: 82194

Disponível em: https://www.nucleodoconhecimento.com.br/educacao-fisica/manualde-praticas 
Figura 7 De volta ao menu inicial, clicando em "Feedback", abre-se uma tela onde o usuário pode participar de uma coleta de dados, importante para continuação da pesquisa do autor do aplicativo, nesta área de conhecimento.

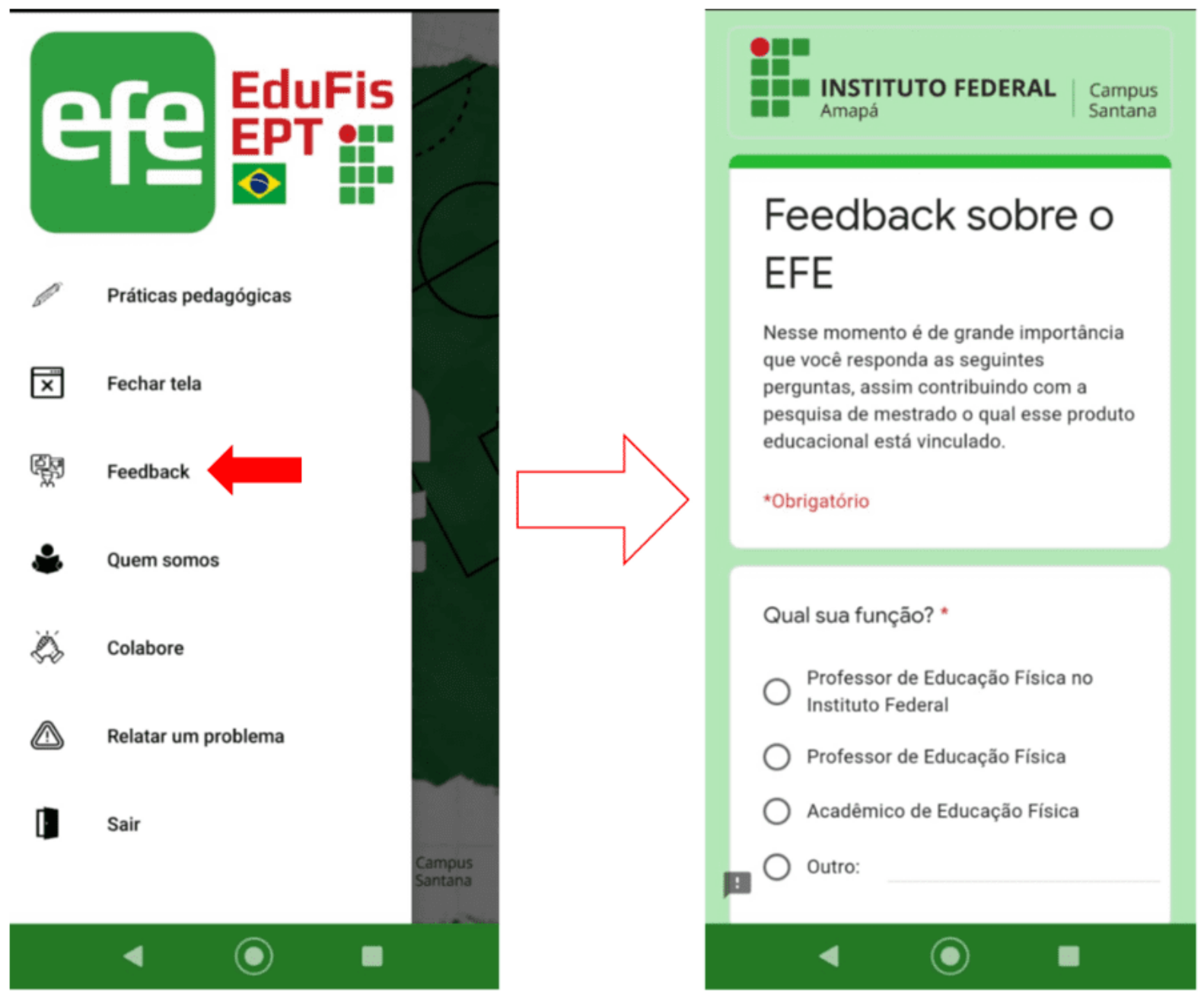

RC: 82194

Disponível em: https://www.nucleodoconhecimento.com.br/educacao-fisica/manualde-praticas 
Figura 8 Ao pressionar o botão "Quem Somos", ainda no menu principal, o usuário terá acesso a informações dos autores do aplicativo, bem como a seus currículos na Plataforma Lattes.
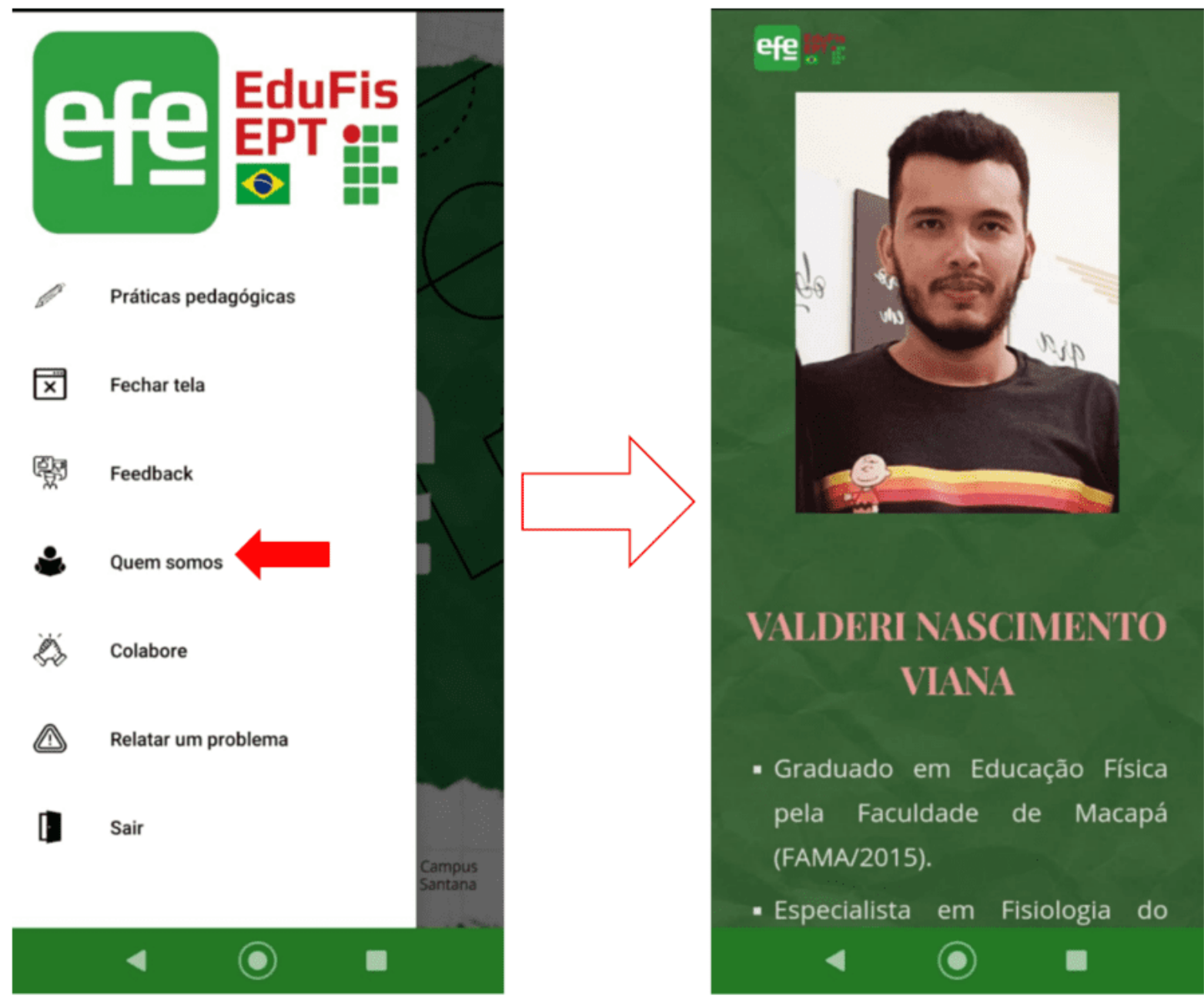

RC: 82194

Disponível em: https://www.nucleodoconhecimento.com.br/educacao-fisica/manualde-praticas 
Figura 9 No menu, ao clicar em "Colabore", o usuário pode colaborar na melhoria do conhecimento dentro deste APP e no site, enviando em formato PDF ou DOC, com sua prática pedagógica própria e com avaliações direcionadas pelo aplicativo. Levase em conta que não se constrói conhecimento de modo solitário.
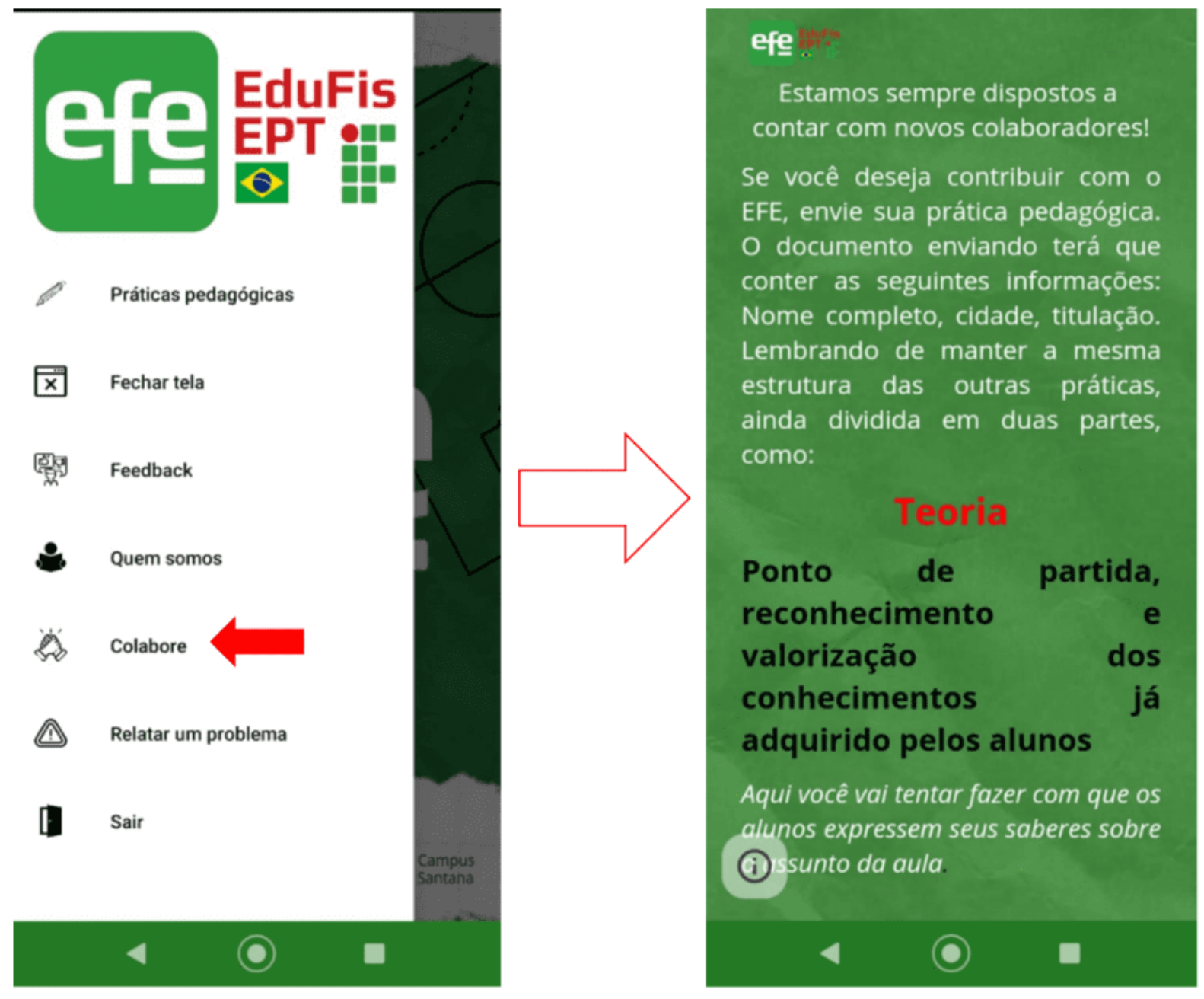

RC: 82194

Disponível em: https://www.nucleodoconhecimento.com.br/educacao-fisica/manual- 
Figura 10 No menu ainda é possível clicar para "Relatar um problema" no aplicativo, clicar para "Fechar Janela" ou ainda clicar para "Sair".

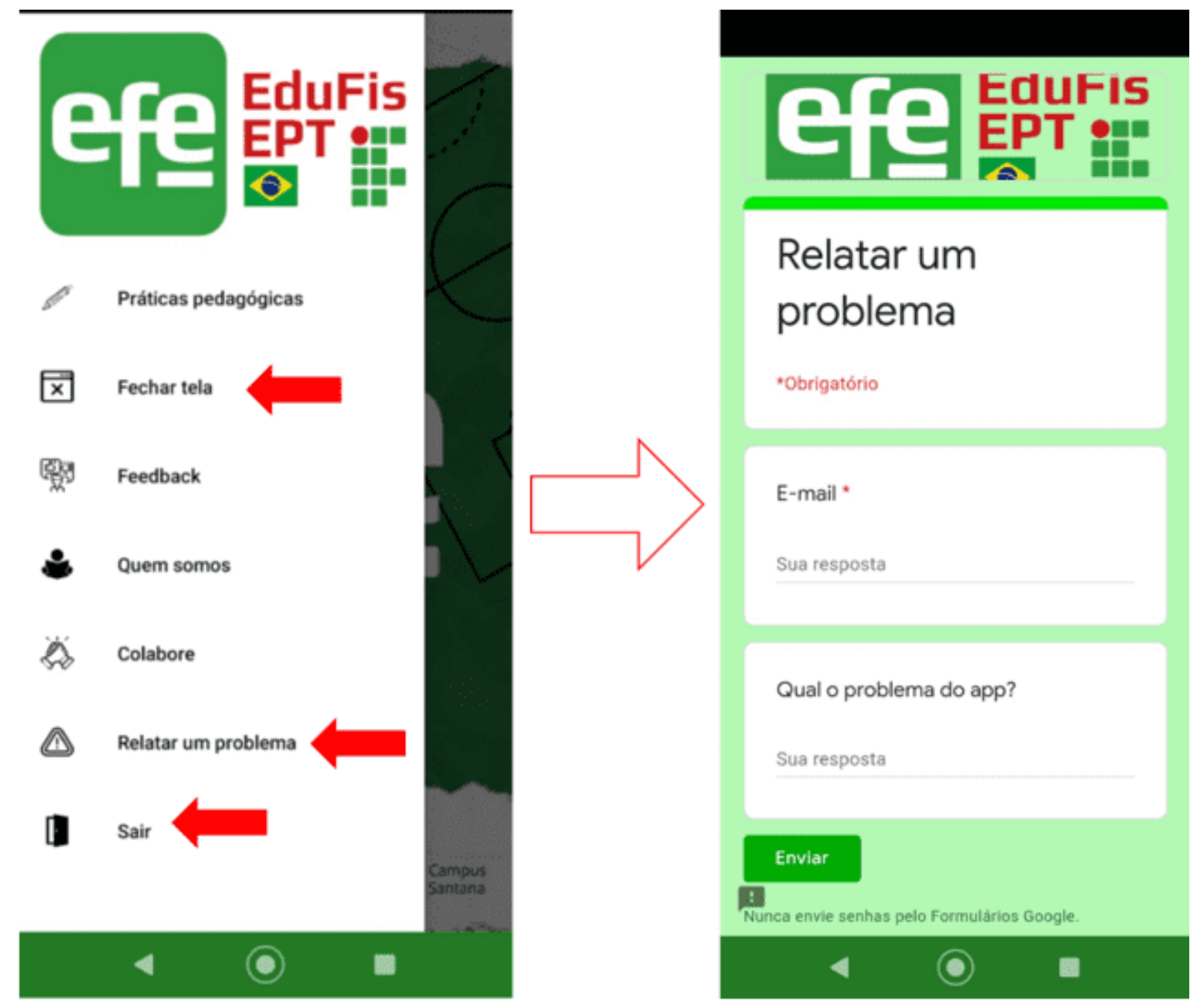

\section{O CONTEÚDO}

Com acesso fácil e rápido pelo aplicativo para Android ou através do site, o conteúdo tem a ambição de mostrar a parte teórica da formação humana, integral e omnilateral de toda atividade prática disponibilizada.

RC: 82194

Disponível em: https://www.nucleodoconhecimento.com.br/educacao-fisica/manualde-praticas 
Para isso contou com arcabouço teórico pesquisado pelo autor durante sua pósgraduação Stricto sensu, assim como a prática também derivou de pesquisa, muita realizada em nível regional.

Figura 11 Mostra parte da teoria dentro do item "Jogos e brincadeiras".

\section{Jogos-e:brincadeiras?l}

Teorian

Ponto de partida, reconhecimento e valorização dos conhecimentos jáadquirido pelos alunos

ฯ

O professor faz a utilização do vídeo "Documentário:- Terreiros do- Brincar". (https://www.youtube.com/watch?v=29yJW7XQUws - ). - Após-a exibição-o-docentepergunta qual o detalhe que mais chamou atenção no video, para envolver a realidade dos. alunos, - o professor questiona:-Quem gosta de brincar?-Quais as brincadeiras que vocês mais gostavam na infância?; e-agora, qual sua brincadeira favorita?

\section{Como pratica-social, questões que podem'ser resolvidas/debatidas} com o auxílio deste conteúdo. sugestões das dimensões teórico-práticas: ๆ

-Conceitual: O que-são brincadeiras? $-\uparrow$

- Cultural: $\mathrm{O}$ brincar-é-só coisa de criança? -1

RC: 82194

Disponível em: https://www.nucleodoconhecimento.com.br/educacao-fisica/manualde-praticas 
-Psicológica/Histórica:-Qual-a-importância-do-brincar?ף

-Social:Por-que na-vida-adulta-somos-obrigados-a esquecer-as-brincadeiras?-

ๆ

Encaminhamento-metodológico para-a-explicação-do-conteúdo

Exibição-integral-ou parcial- do- documentário- "Tarja-Branca". - Disponivel-em. https://www.videocamp.com/pt/campaigns/quarentena-believe-

tarjabranca/player?special_id $=84100 \ldots$

O professor-vai fazer uma reflexão sobre o documentario e abordar assuntos como: brincadeira e a vida adulta; como - mercado-de trabalho-subtrai-das pessoas os momentoslúdicos-e-a-importância-dessa-pratica-para-a-saúde, fazendo-sempre-uma-ligação-com·ovideo exibido -1

\section{Formação,-atitudes-e-valores}

Ao final, o aluno tenha a atitude de perceber que mesmo deixando a infäncia nunca. parou-de-brincar, apenas-mudou-o-modo-e formas.-Durante-essa pratica-trabalha-com-0. aluno-a-cooperação, uniâo, senso-critico-e-criatividade.

RC: 82194

Disponível em: https://www.nucleodoconhecimento.com.br/educacao-fisica/manual- 
Figura 12 Mostra algumas das práticas pesquisadas e descritas dentro do item "Jogos e brincadeiras", sempre subdivididas em "Recursos" (necessários para montar a prática), "Descrição" (método ou regra a seguir para que a prática funcione) e "Dica" (sempre uma outra visão sobre a prática).

\section{Minhas memórias \\ T \\ Recursos:-folha-de-A4, canetas}

Descrição: Em sala, -solicitar dos alunos que em uma folha-de-A4 faça um resgate de -suasmemorias as mais antigas, clara e-alegre, momentos de brincadeiras-de-sua infäncia. Podeser um brinquedo, um -momento-especifico-como -uma-viagem, uma festa, férias. E-comisso, construir-a partir-dessas-lembranças como elas -se-conectam com-sua-vida-atual. -

Dicas:- Caso-0 aluno tenha-algum - registro,-no-grupo- de-WhatsApp-os-alunos-podemmandar a foto junto com um audio (Possivel ensino remoto), para-isso, o professor precisamarcar-um-dia-especifico.- Ou-pode-ser-feito-em-sala-de-aula, - o-qual-cada-um-leva-seuregistro-e-comenta- 9

\section{Danca'da.Cadeira,}

Recursos:-Cadeiras, caixa-de-som -

Descrição:- Será - formado - uma-roda-com-as - cadeiras-e - os alunos ficarão-a- sua-volta, contendo-uma-cadeira-a-menos que-o-número-de participantes. Ao-som-da-música-osalunos-vão-andar-ao-redor-da-roda-(dançando-no-ritmo-da-música)- Quando-a-músicapausar-cada-integrante-ocupa-uma-cadeira, - sempre-sobrando um-sem, ficando-fora-dadança.-A cada nova rodada fica sempre com uma cadeira-a menos até sobrar apenas umae-dois-alunos, que tentaram ocupá-la, tornando-se-assim, - o vencedor.-

Dica- $\mathrm{O}$ - professor pode-diversificar-como- os - alunos-andam - ao redor - da-roda, dandoinstruções como:-Mais rápido; mais lento; andar-de costas; mão na cabeça; indo de acordo com-a-criatividade-do professor. .

RC: 82194

Disponível em: https://www.nucleodoconhecimento.com.br/educacao-fisica/manual- 


\section{Quem·Sumiu?·}

Recursos:-Tecido,-sala-de-aulaf

Descrição:-Em-sala-de-aula-ou-na-quadra-um-aluno-será-escolhido, antes-de-ter-os-olhosvendados, -vai-olhar para-a turma, - logo-depois-ficar-de-costas e-será-vendado, enquantoisso um aluno-selecionado-sai-do-local, 0 -aluno-com 05 -olhos cobertos-vira-de frente paraturma e tira-a-venda, com isso, terá que adivinhar quem sumiu do local - O que estava foraretorna e ocupa- - lugar de quem deveria-descobrir - 0 -integrante que estava-faltando. -

Dica: $O$ - professor pode autorizar-até-3 - características-do-aluno que-sumiu, tal-duvidasendo respondida pelos-alunos-da-turma-f

\section{Esconder-Objetos,}

Recursos:-20-Bolinhas-de plástico, -1

Descrição:A-turma-será-dividida-em-2-times. Uma-equipe-sai-da-sala-e pela-quadra-oupor-determinado espaço-dentro da-escola-tem que-esconder-os-objetos-(dentro-de-uns-3. minutos). Otime que ficou na-sala aguardando quando autorizado pelo professor -sai paraprocurar-os-objetos, por-um-tempo-limitado-Cada-objeto-encontrado-é-marcado-umapontuação para-o-time, essa pontuação pode-ser-definida pelas-cores-das-bolinhas. -

\section{CONCLUSÕES}

Com sua interface simples, o uso do aplicativo se torna fácil e com funcionalidades intuitivas. Este produto educacional existe como suporte para que o professor desenvolva uma educação física mais crítica, que entenda o aluno além do ser biológico, ou seja, um ser social, político, cultural e histórico. Em que cada aula, o aluno poderá compreender que o conteúdo apresentado está ligando a várias dimensões da realidade, contribuindo para uma visão de sociedade baseada em valores e atitudes para o objetivo comum: conhecimento para gerar menos exclusões e discriminações.

RC: 82194

Disponível em: https://www.nucleodoconhecimento.com.br/educacao-fisica/manual- 


\section{REFERÊNCIAS}

ANDRADE, L C; ANDRADE, J.S.D; ALMEIDA S.M. Pedagogia histórico-crítica e Educação Física: o ensino das práticas corporais de aventura nos anos iniciais. Motrivivência, v. 32, n. 63, p. 01-15, 2020.

SANTOS, L. S; PORTO, C. D.; OLIVEIRA, K. E. J. Whatsapp e ciência-a conectividade científica por meio da divulgação. C\&D-Revista Eletrônica da FAINOR, v. 11, n. 2, p. 271-289, 2018.

SILVA, M. B. Contribuições Da Educação Física Escolar Para A Formação Omnilateral Do Ser Social: Uma Reflexão À Luz Da Psicologia Histórico-Cultural E Da Pedagogia Histórico-Crítica. Germinal: Marxismo e Educação em Debate, v. 9, n. 2, p. 249, 2017.

VIANA, V. N. et al. Quadras de esportes em condições de uso adequado no Brasil: influência no ensino-aprendizagem nas aulas de Educação Física (2015). Research, Society and Development, v. 9, p. e239985704-14, 2020.

VIANA, V. N.; DIAS, C. A. G. M. Educação Física e EPT. São Paulo SP: Centro de Pesquisa, 2020. 45p. Disponível em: < https://www.nucleodoconhecimento.com.br/livros/educacao/educacao-fisica-e-ept >.

DOI: 10.32749///educacao/educacao-fisica-e-ept ISBN: 978-65-86069-90-7

Enviado: Abril, 2021.

Aprovado: Abril, 2021.

RC: 82194

Disponível em: https://www.nucleodoconhecimento.com.br/educacao-fisica/manualde-praticas 